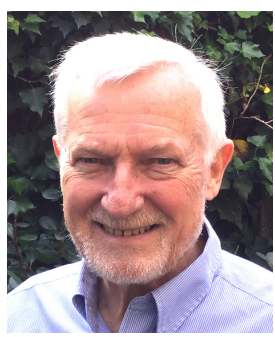

\section{Ben Boer}

Distinguished Prof

RIEL, Wuhan University

Emeritus Prof, University of Sydney

Deputy Chair, IUCN World Commission

on Environmental Law

\section{DEVELOPING A GLOBAL SOIL REGIME}

\author{
lan Hannam \\ Adj Associate Prof \\ Aglaw Centre UNE \\ Co-Chair, Sustainable Soil \\ and Agriculture Specialist \\ Group, IUCN World \\ Commission on \\ Environmental Law
}

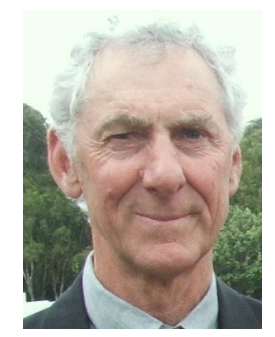

From the 1960s onwards, the global community became more aware of the phenomena of air and water pollution. More recently, the issues of climate change, loss of biodiversity, desertification, drought, and land degradation have become more prominent. While biodiversity loss and climate change have garnered close attention, issues of land degradation and sustainability of soils has attracted less focus in international fora and by national governments. We argue here that soil, as a vital biological and cultural resource, demands attention on the same level as biological diversity and climate change, and that this should be reflected in both international law and in legislation at national level. This article explores the elements that could form the basis of a global instrument for the conservation and sustainable use of soil, and sets out the premise for the community of nations to support the negotiation and drafting of such an instrument. It does so in light of the recent discussion on the introduction of a provision in the United Nations Sustainable Development Goals on the achievement of zero net land degradation, the revision of the World Soil Charter as well as the work of the UN Special Rapporteur on the Right to Food. It also briefly explores other complementary mechanisms that can be used for promoting the sustainable use of soils.

\title{
Introduction
}

In this 2015 International Year of Soils, ${ }^{1}$ one of the most fundamental of global resources is at last attracting a higher profile within governmental and institutional realms around the world. This article argues that this increased attention now needs to be translated into political and legal action. The Revised World Soil Charter of 2014 reminds us that '[s]oils are a key enabling resource, central to the creation of a host of goods and services integral to ecosystems and human well-being. The maintenance or enhancement of global soil resources is essential if humanity's overarching need for food, water, and energy security is to be met'. ${ }^{2}$ As a basic terrestrial foundation of human development, soil sustains societies around the world through agriculture, grazing, forestry and maintenance of water sources, and represents a wide range of cultural values.

Although soil has been the poor cousin compared with the attention that has been given to the loss of biological diversity, the effects of climate change and reduction in food security, ${ }^{3}$ it is an essential aspect of all three of these important phenomena, as recognised in the 2015 Soil Atlas:

FAO, Healthy Soils for Healthy Life (2015) 2015 Year of Soils <http://www.fao.org/soils-2015/about/en/>.

Global Soil Partnership and FAO, Revised World Soil Charter 2014

<http://www.fao.org/fileadmin/user_upload/GSP/docs/ITPS_Pillars/annexVII_WSC.pdf>; the UN Food and Agriculture Organization negotiated the updating of the 1982 World Soil Charter as part of the establishment of the Global Soil Partnership, established in 2013, and comprises a wide range of governments, institutions and non-state actors: <http://www.fao.org/globalsoilpartnership/partners/en/>

3 As an indicator of the comparatively low status of soil and land degradation, we see that in the preambles of the 1992 Climate Change Convention and the 1992 Biodiversity Convention, climate change and biodiversity are regarded as matters of 'common concern of humankind', whereas the 1994 Convention to Combat Desertification, as the only international instrument that focuses on land degradation (and then only in drylands), does not include this phrase. See B Boer, 'Land Degradation as a Common Concern of Humankind', in F Lenzerini, and A Vrdoljak (eds), International Law for Common Goods (Hart, 2014). 
The world community has set itself three major goals that cannot be reached without soil conservation: to stop the loss of biodiversity by 2020, to limit global warming to 2 degrees Celsius, and to ensure everyone access to enough food. We can achieve none of these goals without appropriate policies to conserve the soil and use land in a more sustainable way. But all of the more than 200 international treaties, agreements and protocols neglect soil conservation and fail to define specific targets. ${ }^{4}$

The patterns of vulnerability of soils to environmental and socioeconomic changes have been well documented from a scientific point of view, and provide a good basis for analysis of the interacting pressures that affect the overall stability of soils at the global level. ${ }^{5}$ This has provided information on which to draft a global soils instrument and to prepare legislation directed to reducing the vulnerability of soil to degradation.

To avoid the catastrophic effects of serious and widespread soil degradation, legally based sustainable land management regimes to promote the conservation and sustainable use of soils must be developed, based on clear understandings of the technological, sociological, economic and ecological issues that affect soil. Human induced soil degradation is caused by processes and activities generated by various technologies and, in some cases, substances. These actions threaten the ecological integrity of soil, causing a loss of the soil's functions.

In formulating appropriate legal frameworks, the issues of human rights, population dynamics, poverty, human health, food security, globalisation processes, land use conflicts, climate change mitigation and adaptation, conservation of biodiversity, the management of water and forests and natural resource governance in general must be taken into account. Another matter is the direct impact of urban development. ${ }^{6}$

Further issues involve the involuntary migration and displacement of people and communities from productive lands into marginal ecological and economic areas because of ethnic and religious conflict and associated deprivation and violence, and the more recent phenomenon of the purchase or lease of productive agricultural lands in poorer countries by richer countries. ${ }^{7}$ These issues undermine sustainable livelihoods and economic development as well as the capacities of societies and individual nations. They result in degradation of soil, and contribute to lower levels of human well-being and higher levels of vulnerability, deprivation and disadvantage. Improving human well-being by protecting soil has become a moral imperative and a critical aspect of human rights in recent years, particularly from the point of view of food security. ${ }^{8}$

On the basis of these concerns, we submit that there is an urgent need for the international community to embrace the development of a treaty on the conservation and sustainable use of soils. Many of the matters mentioned above have become part of the debate with regard to the formulation of the United Nations (UN) Sustainable Development Goals (SDGs). ${ }^{9}$ The SDGs are likely to form the basis of global environmental policy for the next couple of decades. We argue that some bold forward steps are now urgently required, and that these steps must be taken with an eye to the SDGs. For environmental lawyers, the challenge is to ensure that the SDGs acquire legal teeth. We also briefly examine policy documents and multi-lateral environmental agreements also relevant to the development of a robust international and national legal regime for the protection of the world's soils. We then address the possibilities with respect to such a regime.

\footnotetext{
${ }^{4}$ The Soil Atlas, Facts and Figures about Earth, Land and Fields 2015, (Heinrich Böll Foundation and Institute for Advanced Sustainability Studies, 2015) ('The Soils Atlas 2015').

5 G J Churchman and E R Landa, The Soil Underfoot: Infinite Possibilities for a Finite Resource (CRC Press, 2014).

6 In this regard, the Soil Atlas 2015, above n 4, 15, states: 'Cities and towns currently occupy only 1-2 percent of the world's land. By 2050, they will cover 4-5 per cent - an increase from 250 to 420 million hectares'.

'Major investors now see land in foreign countries as an attractive asset. Over the last decade, they have bought or leased large areas, especially in developing countries, for farming, mining, tourism and other uses. Governments welcome the influx of cash in the hope that it will stimulate the economy. But these land acquisitions are controversial; opponents speak of “land grabbing"'. The Soil Atlas 215, above n 4, 39; see also Michel Durousseau, Quelle Stratégie pour la Diversité Biologique et la Protection Fonciere des Espaces Naturels et Ruraux de la Planète? (Which Strategy for Biological Diversity and Natural and Rural Land Protection of the Planet?) Legal Instruments for the Implementation of Sustainable Development (Republique Française, 2012) 239 ff.

8 See UNCCD. 'Human Rights and Desertification: Exploring the Complementarity of International Human Rights Law and the United Nations Convention to Combat Desertification: Desertification, Land Degradation and Drought' (Issue Paper No 1, Secretariat of the United Nations Convention to Combat Desertification in cooperation with the Swiss Agency for Development and Cooperation, Druck Center Meckenheim GmbH, 2008) <http://www.ohchr.org/Documents/Issues/ ClimateChange/Submissions/UNCCD.pdf>; see also UN Special Rapporteur on the Right to Food <http://www.ohchr.org/EN/Issues/Food/Pages/Foodlndex.aspx>.

9 Open Working Group Proposal for Sustainable Development Goals, A/68/970 <https://sustainabledevelopment.un.org/content/documents/1579SDGs\%20Proposal.pdf>.
} 


\section{Sustainable development goals}

The Rio+20 Conference 2012 had before it a major proposal to develop a set of SDGs to replace the Millennium Development Goals (MDGs) prepared by the UN in the early 2000s. The SDG's are intended to converge with the post-2015 development agenda. ${ }^{10}$ They are being prepared on the basis of an 'inclusive and transparent intergovernmental process open to all stakeholders, with a view to developing global sustainable development goals to be agreed to by the UN General Assembly'. ${ }^{11}$ The Rio+20 Outcome Document, The Future We Want, ${ }^{12}$ had already included paragraphs focusing on desertification, degradation and drought. The background to these three paragraphs includes the fact that the Secretariat of the United Nations Convention to Combat Desertification had already carried out research and had prepared a policy brief relating to the concept of land degradation neutrality in the SDGs. ${ }^{13}$

Paragraph 205 of the The Future We Want contextualised the issues of desertification, degradation and drought. It recognised 'the economic and social significance of good land management, including soil, particularly its contribution to economic growth, biodiversity, sustainable agriculture and food security, eradicating poverty, women's empowerment, addressing climate change and improving water availability'. It also urged that 'desertification, land degradation and drought are challenges of a global dimension and continue to pose serious challenges to the sustainable development of all countries, in particular developing countries'. Further, paragraph 206 recognises 'the need for urgent action to reverse land degradation. In view of this, we will strive to achieve a land-degradation neutral world in the context of sustainable development'. Paragraph 207 sets out a broad framework for national, regional and international action in order to monitor land degradation and to restore degraded lands in arid, semi-arid and dry sub-humid areas.

The Rio+20 paragraphs referred to above have been reflected in proposed SDG 15, where the question of desertification and land degradation is placed in the broader context of terrestrial ecosystems, forest management and biodiversity loss. ${ }^{14}$ Goal 15 states:

Protect, restore and promote sustainable use of terrestrial ecosystems, sustainably manage forests, combat desertification, and halt and reverse land degradation and halt biodiversity loss.

The sub-paragraphs to Goal 15 focus on the specific ecosystem elements; the most pertinent from the point of view of land and soils are:

15.1: by 2020, ensure conservation, restoration and sustainable use of terrestrial and inland freshwater ecosystems and their services, in particular forests, wetlands, mountains and drylands, in line with obligations under international agreements.

15.2: by 2020 , promote the implementation of sustainable management of all types of forests, halt deforestation, restore degraded forests, and increase afforestation and reforestation by $\mathrm{x} \%{ }^{15}$ globally.

15.3: by 2020 , combat desertification, and restore degraded land and soil, including land affected by desertification, drought and floods, and strive to achieve a land-degradation neutral world. ${ }^{16}$

We will now discuss the concept of zero net land degradation and land degradation neutrality.

\footnotetext{
${ }^{10}$ See Preparing for the Development Agenda beyond 2015, UN Department of Economic and Social Affairs (DESA) <http://www.un.org/en/development/desa/policy/untaskteam_undf/index.shtml>; Millennium Development Goals and Post-2015 Development Agenda, UN ECOSOC <http://www.un.org/en/ecosoc/about/mdg.shtml>.

${ }^{11}$ Open Working Group, 17 Sustainable Development Goals, Sustainable Development $<$ http: / / sustainabledevelopment.un.org/?menu=1300>.

12 The Future We Want, UN Doc A/66/L 56 <http://www.un.org/ga/search/view doc.asp?symbol=A/RES/66/288\&Lang=E>.

${ }^{13}$ See UNCCD, 'Zero Net Land Degradation: A Sustainable Development Goal for Rio+20: To Secure the Contribution of our Planet's Land and Soil to Sustainable Development, Including Food Security and Poverty Eradication' (Secretariat Policy Brief, May 2012) <http://www.unccd.int/Lists/SiteDocumentLibrary/Rio+20/UNCCD_PolicyBrief_ZeroNetLand Degradation.pdf>. This Policy Brief drew on a longer research report for the UNCCD: R Lal, U Safriel and B Boer, 'Zero Net Land Degradation: A New Sustainable Development Goal for Rio+ 20' (report prepared for the UNCCD Secretariat, May 2012) <http://www.unccd.int/Lists/SiteDocumentLibrary/secretariat/2012/Zero\%20Net\%20Land\%20Degradation\% 20Report\%20UNCCD\%20May\%202012\%20background.pdf>.

${ }^{14}$ Other Goals relevant to soil include SDG 2, 'End hunger, achieve food security and improved nutrition and promote sustainable agriculture', para 2.4, which focuses on sustainable food production systems, resilient agricultural practices that increase productivity and production; SDG 3 on Health and para 3.9 focusing on reducing 'the number of deaths and illnesses from hazardous chemicals and air, water and soil pollution and contamination'; SDG 12 'Ensure sustainable consumption and production patterns' and para 12.4 focusing on 'environmentally sound management of chemicals and all wastes throughout their life cycle, in accordance with agreed international frameworks, and significantly reduce their release to air, water and soil in order to minimize their adverse impacts on human health and the environment'.

15 The exact percentage is yet to be negotiated.

${ }^{16}$ Open Working Group Proposal for Sustainable Development Goals, Sustainable Knowledge Platform <https://sustainabledevelopment.un.org/content/documents/1579SDGs\%20Proposal.pdf>.
} 


\section{Zero net land degradation}

The concept of zero net land degradation (ZNLD) that emerged at Rio+20 in 2012 was defined in a UNCCD policy brief as: ' $[T]$ he achievement of land degradation neutrality, whereby land degradation is either avoided or offset by land restoration. Promoting the ZNLD target would secure currently available productive land for the use of present and future generations'. The concept of land degradation neutrality inherent in this definition is explained in the policy brief as being achieved 'when globally or in a given landscape or terrestrial ecosystem the area of productive land (and therefore sustainable land use) remains stable or increases'. ${ }^{17}$ The policy brief sets out key actions that can be taken by the international community to ensure progress on ZNLD, including:

1. Agree on a Sustainable Development Goal at Rio+20 for Zero Net Land Degradation

2. Agree on a new legal instrument (such as a Protocol on Zero Net Land Degradation) to the UNCCD as a global policy and monitoring framework to focus efforts and empower the international community to act with the speed and scale required to address this crucial problem.

The UNCCD Secretariat proposed that the envisioned protocol on ZNLD to the Desertification Convention would facilitate ${ }^{18}$ (in summary): incorporation of emerging economic instruments; including payments for ecosystem services such as carbon sequestration; water conservation for preventing degradation of non-degraded land; supporting the restoration of already degraded land; and negotiation and setting of achievable and verifiable targets for ZNLD. The targets were envisioned to include:

- Zero net land degradation by 2030,

- Zero net forest degradation by 2030, and

- Drought policies and drought preparedness measures implemented in all drought-prone regions/countries by 2020.

Since Rio+20, the legal aspects of ZNLD and land degradation neutrality have been discussed at a wide variety of meetings and conferences. ${ }^{19}$ The question in the context of this article is how these aspirations can be translated into legally enforceable provisions, at international and national levels. Before considering this, we explore a range of issues that have a bearing on the way in which a new legal regime should be framed. These include the links between soil degradation, climate change, poverty, human rights and food security.

\section{Climate change, poverty and soil}

An increasingly important issue for land degradation and the sustainable use of soil is the effect of climate change. Risks to soil stability are increasing as a result of the continuing concentration of people in highly exposed areas. The capacity of communities to adapt is affected by a state's social protection schemes and the adequacy of infrastructure, as well as conflict between communities competing for land resources. Poverty must be addressed if vulnerability to both environmental and socio-economic changes is to be reduced, as the most impoverished people often occupy areas of poor quality soil. ${ }^{20}$ Soil law must play a much more effective role in improving access to material assets - at the household level, and at the community and

\footnotetext{
${ }^{17}$ See UNCCD Policy Brief (2012), above n 13, 6.

18 Ibid; see also UNCCD, A Stronger UNCCD for a Land Degradation Neutral World (Secretariat Issue Brief, 2013).

${ }^{19}$ For eg, IISD Reporting Services, First Global Soil Week: Soils for Life (November 2012 <http://www.iisd.ca/soil/gsw1/html/crsvol206num1e.html>; UNCCD, 2nd Science Conference: Economic Assessment of Desertification, Sustainable Land Management and Resilience of Arid, Semi-Arid and Dry Sub-Humid Areas (Bonn, April 2013) <http://2sc.unccd.int/home/>; UNCCD, Consultative Meeting of Experts on a Sustainable Development Goal (SDG) on Land Degradation Neutral World (LDNW) and on the target of Zero Net Land Degradation (ZNLD) (26-27 June 2013); <http://www.unccd.int/en/programmes/RioConventions/RioPlus20/Pages/LDNW-Expert-Meeting.aspx>; UNCCD, COP11 (Windhoek Namibia, September 2013); Second Global Soil Week in October 2013; Global Soil Week 2013: Losing Ground? 27-31 October 2013, IISD Reporting Services, http://www.iisd.ca/download/pdf/sd/crsvol206num2e.pdf; German Environment Agency International Legal Expert Workshop on Land Degradation (December 2014); Third Global Soil Week (GSW) 2015 - 'Soil. The Substance of Transformation', (Berlin, 19-23 April 2015), IISD Reporting Services, <http://www.iisd.ca/soil/gsw3/>.

20 'It is estimated that 50 per cent of these 854 million hungry people live in marginal, dry and degraded lands. Half of the world's hungry people therefore depend for their survival on lands which are inherently poor and which may be becoming less fertile and less productive as a result of the impacts of repeated droughts, climate change and unsustainable land use'. UNCCD 2008, above n 8, 7; see also International Bar Association Climate Change Justice and Human Rights Task Force Report, Achieving Justice and Human Rights in an Era of Climate Disruption (2014) <http: / / www.ibanet.org/PresidentialTaskForceClimateChangeJustice2014Report.aspx>
} 
national levels - to help break the cycle of impoverishment, vulnerability and soil degradation. ${ }^{21} \mathrm{~A}$ related rights issue is the question of involuntary migration as a result of the effects of climate change. ${ }^{22}$

\section{Human rights, land degradation and sustainable use of soil}

The Future We Want reaffirmed the need to be guided by the purposes and principles of the Charter of the United Nations, with full respect for international law and its principles. It emphasises the importance of freedom, peace and security, respect for all human rights, including the right to development and the right to an adequate standard of living, including the right to food and water, the rule of law, good governance, gender equality, women's empowerment and the overall commitment to just and democratic societies for development. It also reaffirmed the importance of the Universal Declaration of Human Rights, as well as other international instruments relating to human rights and international law. ${ }^{23}$ In early 2015, at Global Soil Week, Klaus Töpfer reinforced these concepts in the soil context: 'Soil protection and soil rehabilitation policies need to be based on a human rights framework, principally emphasizing land rights for marginal and vulnerable groups in society'. ${ }^{24}$

As a further aspect of human rights, explicit recognition of the role of women in agriculture and natural resources management, and empowering them to participate in decision-making will contribute to widely shared objectives of equity and justice as well as making good economic, environmental, cultural and social sense. Gender-sensitive poverty alleviation programs in rural areas should thus be a central component of strategies to address sustainable soil issues. ${ }^{25}$ Additionally, better access to education is essential to increase personal capacities, and is fundamental for promoting intergenerational equity.

\section{Food security and soil}

Article 11 of the 1966 International Covenant on Economic, Social and Cultural Rights ${ }^{26}$ is explicit with regard to food security and alleviation of hunger. In summary, it states that everyone has the right to an adequate standard of living for themselves and their family, including adequate food, clothing and housing, and to the continuous improvement of living conditions, and that state parties should take appropriate steps to ensure the realisation of this right. It recognises the fundamental right of everyone to be free from hunger, and obliges states to take measures to improve methods of production, conservation and distribution of food.

The question of food security has increasingly engaged the attention of policymakers in recent years, and is part of a broader set of questions concerning the right to the enjoyment of a safe, clean, healthy and sustainable environment. ${ }^{27}$ Food security represents a range of complex issues, related to population increase, increase in demand for land and other resources, overconsumption, decline of agricultural production, lack of availability of good quality agricultural land, inconsistency of water supply, inequities in food availability and distribution, and a move away from agriculture and grazing activities to industrial and service industries. The United Nations has placed a good deal of emphasis to the right to food over many decades,. In addition to the human rights instruments, the first of the MDGs emphasised the reduction of hunger, and the first UN

\footnotetext{
${ }^{21}$ See H Hurni and U Weismann (eds), Global Change and Sustainable Development: A synthesis of Regional Experiences from Research Partnerships - Perspectives of the Swiss NCCR North-South,(Geographica Bernesia, vol 5, 2010).

22 This issue is not further pursued here, but see J McAdam, Climate Change, Forced Migration, and International Law (Oxford University Press, 2012); and S Gruber, 'Human Displacement and Climate Change in the-Asia Pacific' in B Boer (ed) Environmental Law Dimensions of Human Rights (Oxford University Press, 2015).

${ }^{23}$ The Future We Want, above n 12.

${ }^{24}$ K Töpfer 'Transformation is Needed - Transformation is Possible' (Chairman's Conclusions, Global Soil Week, April 2015) 3 <http://globalsoilweek.org/wp-content/uploads/2015/04/150422_Chairman_Conclusions.pdf>.

${ }^{25}$ Gender equality and women's empowerment has become an inherent aspect of the SDG debate; see para 11, Open Working Group Proposal, above n 13; and SDG 5 'Achieve gender equality and empower all women and girls'.

${ }^{26}$ The International Covenant on Economic, Social and Cultural Rights forms part of a package of human rights instruments which is collectively known as the International Bill of Human Rights, which includes this Covenant, the 1966 International Covenant on Civil and Political Rights and the 1948 Universal Declaration of Human Rights. The Universal Declaration recognised the right to food in art 25.

27 This is the subject of investigation by the UN Special Rapporteur on Human Rights and the Environment, John Knox, appointed in 2012. See Office of the Commissioner on Human Rights 'Special Rapporteur on human rights and the environment (former Independent Expert on human rights and the environment) <http://www.ohchr.org/EN/Issues/Environment/SREnvironment/Pages/SRenvironmentlndex.aspx>.
} 
resolution on the matter was passed in $2000 .{ }^{28} \mathrm{~A}$ Special Rapporteur on the Right to Food was appointed in the same year, with successors appointed in 2008 and $2014 .{ }^{29}$ The right to food is defined as:

The right to have regular, permanent and unrestricted access, either directly or by means of financial purchases, to quantitatively and qualitatively adequate and sufficient food corresponding to the cultural traditions of the people to which the consumer belongs, and which ensure a physical and mental, individual and collective, fulfilling and dignified life free of fear. ${ }^{30}$

It is obvious that food security should serve as a strong motivation for an international instrument on the sustainable use of the world's soils.

\section{An ecosystem approach to drafting legislation}

According to Blue Planet Laureate, Gene Likens: 'The ecosystem approach, embracing complexity and inclusiveness rather than avoiding them, provides an important ecological tool for identifying, describing, and addressing multifaceted environmental problems'. ${ }^{31}$ As the well-being of human societies, in some cases even their survival, may depend on a conscious effort to slow down the rate of exploitation of natural resources and loss of biological diversity, an ecosystem approach is required as the basis for the drafting of law and policy. ${ }^{32}$ In current debates, this involves a consideration of the 'environmental rule of law'. ${ }^{33}$ This means, at the least, developing robust legal mechanisms that enable an ecosystem-based approach to be applied in all aspects of soil protection. The ecosystem approach takes into account the relationship between soil bodies as living ecological communities and the broader environmental and landscape context. An effective environmental rule of law that promotes soil sustainability will therefore depend on the selection of appropriate ecological concepts and the development of a legal structure with the right elements to implement these concepts. ${ }^{34}$

With these matters in mind, we argue that to generate the conditions for the sustainable use of soils, governance programs must be integrated from the local to the global level, across a range of sectors, and over a substantial time frame to enable effective soil policy making. Soil legislation that is drafted in such a way that it intersects adequately with other aspects of environmental and natural resources management, and which promotes broad-ranging environmental capacity building and education programs, is essential for enhanced human well-being. Continued emphasis on sustainable soil management at both national and local community levels is critical for increasing the capacity to adapt to environmental changes related to the sustainable use of land and its soil; this is recognised in the 'Guidelines for Action' in the World Soil Charter which states that the 'overarching goal for all parties is to increase the area under sustainable soil management and the area of soils rehabilitated or restored'. ${ }^{35}$

\section{Sources for global soil law ${ }^{36}$}

The international environmental treaties relating to climate change, biodiversity, desertification, trade in hazardous wastes, endangered species, the ozone layer, and wetlands all relate, in one way or another, to the use of the land and its soil. ${ }^{37}$ While several multilateral environmental treaties, including the Biodiversity

${ }^{28}$ See successive resolutions on the right to food at: Overview of the Mandate, Office of the High Commissioner for Human Rights <http://www.ohchr.org/EN/Issues/Food/Pages/Overview.aspx>.

${ }^{29}$ The first two Rapporteurs were Jean Ziegler and Olivier De Schutter, followed by the current Rapporteur, Hilal Elver; see Office of the High Commissioner for Human Rights, 'Special Rapporteur on the Right to Food'

<http://www.ohchr.org/EN/Issues/Food/Pages/Foodlndex.aspxl>.

${ }^{30}$ Ibid.

${ }^{31}$ G E Likens, 'The Ecosystem Approach for Understanding and Resolving Environmental Problems' in R Watson (ed), Environment and Development Challenges: The Imperative to Act (University of Tokyo Press, 2014) 103.

32 See F M Platjouw, 'The Need to Recognise a Coherent Legal System as an Important Element of the Ecosystem Approach', in C Voigt, (ed) Rule of Law for Nature: New Dimensions and Ideas in Environmental Law (Cambridge, 2013) 158.

${ }^{33}$ See United National Environment Programme, Environmental Rule of Law, <http://www.unep.org/delc/worldcongress/Home/tabid/55710/Default.aspx>; and, United National Environment Programme, Advancing Justice, Governance and Law for Environmental Sustainability, Proceedings of the Governing Council/Global Ministerial Environment Forum at its First Universal Session (UNEP/GC27/17, 12 March 2013).

${ }^{34}$ I Hannam and B Boer, Legal and Institutional Frameworks for Sustainable Soils: A Preliminary Report (IUCN, Gland, Switzerland and Cambridge, UK, 2002) 17 <http://iucn.org. / webfiles/doc/library/EPLP-045.pdf>.

${ }^{35}$ Revised World Soil Charter 2014, above n 2.

${ }^{36}$ The following discussion on elements for a global law for soil has drawn on various materials prepared by the IUCN World Commission on Environmental Law, Specialist Group on Sustainable Soil and Agriculture (formerly the Sustainable Use of Soil and Desertification Specialist Group), in its investigations into an international instrument for sustainable use of soil.

${ }^{37}$ This is confirmed by Wyatt, who notes: 'Many international environmental law instruments, both global and regional, binding and non-binding, touch on the protection of soil and its functions to some degree'. A Wyatt, 'The Dirt on 
Convention, the Climate Change Convention and the Convention to Combat Desertification contain elements that can assist in achieving sustainable use of soil, none are sufficient in their own right to form the basis, by way of a protocol of technical annex, to meet the requirements of an international environmental law regime in relation to soil.

At the regional level, several instruments include specific articles on soil as well as articles that can support its sustainable use. ${ }^{38}$ The Protocol on the Implementation of the Convention Concerning the Protection of the Alps of 1991 in the Area of Soil Protection ${ }^{39}$ is the only legally binding instrument specifically focused on the protection of soil. The Protocol provides a basis for improvement of global and national laws for soil in the absence of other legal precedents. A comprehensive survey completed in 2002 investigated the possibilities of national and international environmental laws for soil to guide the development of enhanced legal frameworks for soil. ${ }^{40}$

At the national level, the investigation indicated that states had adopted a variety of approaches to frame domestic soil legislation in order to deal with specific soil protection and land management problems. The global picture that emerged, supplemented by a number of new national soil laws introduced since then, has shown that states have been reasonably innovative in their choice of legal mechanisms to protect soil. ${ }^{41}$ The initial study led to the development of a generic guide for drafting national legislation for sustainable soils. ${ }^{42}$

Soft law instruments and other documents can also be looked to for guidance. For example, Agenda 21, concluded in 1992, contained three chapters on fragile ecosystems, all of which relate to aspects of soil; they focused on deserts, semi-arid lands, mountains, wetlands, small islands and certain coastal areas. ${ }^{43}$

In addition, the Revised World Soil Charter $2014^{44}$ provides some indications for legislative drafting in its mandate. It urges the taking into account of new scientific knowledge with regard to soil pollution and its consequences for the environment, adaption to and mitigation of climate change effects as well as the effects of urban sprawl on both soil availability and soil functions. ${ }^{45}$ With regard to actions by governments, the Charter urges the incorporation of 'the principles and practices of sustainable soil management into policy guidance and legislation at all levels of government, ideally leading to the development of a national soil policy'. ${ }^{46}$ Further, concerning the actions of international organizations, it urges assistance to governments 'on request, to establish appropriate legislation, institutions, and processes to enable them to mount, implement, and monitor appropriate sustainable soil management practices'. ${ }^{47}$ In passing, it can be noted that while the Revised World Charter for Soil provides guidance with respect to priorities, challenges and current concepts, it could certainly be bolstered by more robust language and specific legal prescriptions.

Further, the non-legally binding Draft International Covenant on Environment and Development contains some guidance. Article 24 states:

International Environmental Law Regarding Soils: Is the Existing Regime Adequate?' (2008) 19Duke Environmental Law \& Policy Forum 165, 166.

${ }^{38}$ Hannam and Boer (2002), above $\mathrm{n} 34$.

${ }^{39}$ The Council of the European Union, Decision 2006/516/EC, 27 June 2006, approved the Protocol on Soil Protection on behalf of the European Community. Article (6) of the Decision states, 'One of the main goals of the Protocol on Soil Protection is the safeguarding of the multifunctional role of soil based on the concept of sustainable development. Sustainable productivity of soil must be ensured in its natural function, as an archive of natural and cultural history and in order to guarantee its use for agriculture and forestry, urbanism and tourism, other economic uses, transport and infrastructure, and as a source of raw materials'.

${ }^{40}$ Hannam and Boer (2002), above n 34.

${ }^{41}$ For example, People's Republic of China Water and Soil Conservation Law 1991, revised, commenced March 2011; Soil Protection and Desertification Prevention Law 2012, Mongolia; Islamic Republic of Afghanistan Rangeland Law 2010; Soil Fertility Law 2012, Kyrgyzstan.

42 I Hannam and B Boer Drafting Legislation for Sustainable Soils: A Guide, (IUCN, 2004) <http://app.iucn.org/dbtwwpd/edocs/EPLP-052.pdf $>$. Parts of this Guide are drawn on in subsequent paragraphs.

${ }^{43}$ UN Agenda 21 1992, Chs $\overline{12}, 13$ and 17.

${ }^{44}$ Revised World Soil Charter 2014, above n 2.

45 lbid, Introduction to the Charter.

${ }^{46}$ Ibid, principle $3(\mathrm{v})$.

${ }^{47}$ Ibid. 
Parties shall take all appropriate measures to ensure the conservation and where necessary the regeneration of soils for living systems by taking effective measures to prevent large-scale conversion and soil degradation and loss, to combat desertification, to safeguard the processes of organic decomposition and to promote the continuing fertility of soils. ${ }^{48}$

We would suggest that when the SDGs are finalised, SDG 15 and other related goals ${ }^{49}$ could also be used as a drafting source for an international instrument on soils.

\section{Options for drafting a global instrument on soils}

Informal negotiations and meetings between environmental lawyers and soil scientists over the past decade have canvassed ideas and sought feedback on an appropriate international soil instrument. ${ }^{50}$ The options include: ${ }^{51}$

- A specific and comprehensive treaty with all of the essential legal elements to promote the conservation and sustainable use of soil, and the achievement of zero net land degradation;

- A framework treaty, which sets out basic principles and mechanisms for the sustainable use and conservation of soil, with a protocol subsequently elaborated that fleshes out institutional mechanisms and sets targets for the achievement of zero net land degradation;

- A protocol ${ }^{52}$ or technical annex ${ }^{53}$ to the UN Convention to Combat Desertification focused on setting targets for the achievement of zero net land degradation; ${ }^{54}$

- A protocol to an existing treaty that specifically promotes the sustainable use and conservation of soil. Given the importance of soil from the point of view of biodiversity, this could include the Convention on Biological Diversity and, in terms of significance of soil carbon sequestration, the Framework Convention on Climate Change.

\section{Elements of a global soil instrument}

The more significant legal elements that could be included in an instrument for sustainable use and conservation of soil, regardless of which option is chosen, are addressed below. ${ }^{55}$

\section{Preambular paragraphs}

These paragraphs would set out the key considerations on achieving sustainable soil use and zero net land degradation.

\section{Objective}

In order to emphasise a holistic, ecosystem approach, the objective of an international instrument should recognise soil bodies as integral elements of the terrestrial ecosystem and their critical role in maintaining the earth's biodiversity. The objective should also include reference to the carbon sequestration function of soils. This is also supported, for example, by the Revised World Soil Charter 2014: 'Careful soil management not

${ }^{48}$ IUCN and International Council of Environmental Law, Draft International Covenant on Environment and Development (2010) <https://portals.iucn.org/library/efiles/documents/EPLP-031-rev3.pdf>. The Covenant is undergoing revision in 2015, with the new version taking into account the emerging Sustainable Development Goals.

${ }^{49}$ The following proposed SDGs are relevant to promotion of conservation and sustainable use of soils: 1. Poverty; 2. Hunger, food security, improved nutrition and sustainable agriculture; 3 . Health and well-being; 4. Education; 5 . Gender equality and empowerment; 6. Water; 9. Resilient infrastructure; 10. Reduction of inequality; 11. Cities and human settlements; 12. Sustainable consumption and production patterns; 13 . Climate change; 16 . Promotion of peaceful and inclusive societies for sustainable development; 17. Strengthen the means of implementation and revitalize the global partnership for sustainable development

${ }^{50}$ Over 60 papers and publications on national and international legislative aspects of soil have been prepared by the IUCN World Commission on Environmental Law members.

${ }^{51}$ Initially presented in Hannam and Boer (2002), above n 34, 74-76.

52 Unlike a number of other environmental treaties, the UNCCD does not provide specifically for the preparation of protocols, although such a protocol could, nevertheless, be added by amending the Convention pursuant to art 30 .

${ }^{53}$ Under art 31, the UNCCD provides specifically for the preparation of technical annexes, of which six have been added, focusing on the regional implementation of the Convention. A non-regional technical annex could be added, such as one on the achievement of zero net land degradation.

${ }^{54} \mathrm{~A}$ general annex to the UNCCD mentioned in the previous section could also include provisions as a practical way of implementing the SDG of a land-degradation neutral world (SDG 15), encouraging countries to promote this goal through national legislation and relevant policies.

${ }^{55}$ Many of these elements have appeared in the various drafts of possible instruments that have been prepared by the IUCN World Commission on Environmental Law Specialist Group on Sustainable Soil and Agriculture since 2000, eg, A Protocol and Commentary to the United Nations Convention to Combat Desertification for the Security and Sustainable Use of Soils and to achieve Zero Net Land Degradation (on file with the authors). 
only secures sustainable agriculture, it also provides a valuable lever for climate regulation and a pathway for safeguarding ecosystem services'. ${ }^{56}$

\section{Jurisdictional Scope}

A global soil instrument should apply to the security of global soil resources and use of soils in any manner and for any purpose that may affect the conservation of soil, taking into account risks to the ecological integrity of soil and human health. This should take into consideration the soil's biodiversity in areas within the limits of a state's jurisdiction and, in the case of processes and activities, regardless of where their effects occur, carried out under its jurisdiction or control, within the area of its national jurisdiction or beyond the limits of national jurisdiction. ${ }^{57}$ With respect to areas beyond the limits of national jurisdiction of individual state parties, a global soil instrument should encourage parties to enter into bilateral, regional and multilateral agreements and arrangements regarding transboundary management of soil resources. These arrangements should be consistent with the objective of the instrument and provided so that such provisions concerning soil use do not result in a lower level of protection to soil resources than that provided for by the global instrument. The provisions could form the basis for parties to further expand and integrate the concept of sustainable use of soils within their respective regions. They should also encourage the development of bilateral and regional instruments and arrangements for management of soils. The concept of integrating sustainable development in this way is incorporated in the objectives of the Convention to Combat Desertification 1994, as well as in the objectives of the UN Framework Convention on Climate Change 1992, the Convention on Biological Diversity 1992, and other related instruments. ${ }^{58}$

\section{Key definitions}

One of the most important terms is 'soil security', which considers the conservation of soil fertility, the containment of soil degradation and the reduction of the consequences of drought through improved human livelihoods and wellbeing. ${ }^{59}$ The concept of 'sustainable use of soil' refers to the use of soils in a manner that preserves the balance between the processes of soil formation and soil degradation, while maintaining the ecological functions and protecting and supporting the capacities of soil, thereby maintaining its potential to meet the needs and aspirations of present and future generations. ${ }^{60}$ The concepts of zero net land degradation and land degradation neutrality should also be defined. ${ }^{61}$

\section{Principle}

A global instrument on soil should contain a principle similar to that in article 3 of the Biodiversity Convention; for example:

States have, in accordance with the Charter of the United Nations and the principles of international law, the sovereign right to exploit their own soil resources pursuant to their own environmental policies, and the responsibility to ensure that activities within their jurisdiction or control do not cause damage to the soil resources of other States or of areas beyond the limits of national jurisdiction.

This provision also reflects the issue of jurisdictional scope addressed above.

\section{An international panel for the sustainable use of soils}

A global soil instrument should provide for the establishment of a high-level panel to assess the results of peer-reviewed research and to publish an authoritative assessment of scientific knowledge on soil degradation. ${ }^{62}$ A similar type of action is already required by several multilateral environmental agreements. ${ }^{63}$ Although the Intergovernmental Technical Panel on Soils was established at the first Plenary Assembly of the

\footnotetext{
${ }^{56}$ Revised Soil Charter 2014, Preamble; see also Wyatt, above n 42, 166 who observes that the role of 'soil in regulating the global climate is substantial, and quite complex'.

57 Based on Convention on Biological Diversity 1992, art 4.

${ }^{58}$ Appendix VII of Hannam and Boer (2004), above 42, provides a list of multilateral and regional environmental law instruments and strategies relevant to sustainable use of soil.

${ }^{59} \mathrm{G}$ Kalbermatten et al, Securitizing the Ground, Grounding Security, (UNCCD Secretariat, 2009) <http://www.unccd.int/Lists/SiteDocumentLibrary/Publications/dldd_eng.pdf>; This is supported by the Revised World Soil Charter 2014, above n 2, which recognises that '[S]oils are a key reservoir of global biodiversity, which ranges from micro-organisms to flora and fauna. This biodiversity has a fundamental role in supporting soil functions and therefore ecosystem goods and services associated with soils. Therefore it is necessary to maintain soil biodiversity to safeguard these functions'; see also UNCCD (2008), above $\mathrm{n} 8$.

${ }^{60}$ Hannam and Boer (2002) above n 34, 20.

${ }^{61}$ Using, eg, the definitions from the UNCCD (2012), above $\mathrm{n} 13$, discussed earlier.

${ }^{62}$ See UNCCD (2012), above n 13, sec 5.2 at 53; H Hurni and K Meyer, A World Soils Agenda, Discussing International Actions for the Sustainable Use of Soils (Centre for Development and Environment, 2002) 46.

${ }^{63}$ See, eg art 4(1) (g) and (h) of the Climate Change Convention 1992; art 200 of UNCLOS 1982 and arts 7 and 8 of the Convention on Long-Range Transboundary Air Pollution 1979.
} 
Global Soil Partnership in $2013,{ }^{64}$ it is submitted that such a panel would be much more effective if it were established under a formal legal instrument. The motivation and conceptualisation of an international panel should stress the global nature of the obligations involved, particularly for the benefit of developing countries that lack the human and material resources at present for scientific research and technological development. Such a panel could facilitate the exchange of scientific, technical, environmental and legal information on, and experience with, the use of soils and assist parties to implement a global instrument. ${ }^{65}$ It could ensure that information is made available on the ecological condition of land, ${ }^{66}$ and provide access to other international information exchange mechanisms concerning the use of soil resources.

\section{Capacity building, education and information}

A global instrument for soil should contain a procedure for parties to cooperate in the development and strengthening of human resources, institutional capacity and scientific research capabilities concerning the use of soils. This element would also seek to enhance public knowledge on soils. ${ }^{67}$

\section{Public participation}

Provisions in a global soil instrument regarding the right of access to information and public participation in decision-making regarding decisions on soil could draw on the provisions of the 1998 Convention on Access to Information, Public Participation in Decision-making and Access to Justice in Environmental Matters. ${ }^{68}$ Such a provision should also promote public awareness, education and participation concerning the use of soils.

\section{National legislation for sustainable use of soils}

A global instrument on soil should encourage parties to enact comprehensive national soil legislation, or subnational legislation in the case of federally organised states, including provision for adequate human resources and institutional support systems. The guide prepared by $I U C N^{69}$ for drafting national sustainable soil legislation can be used to identify, develop and strengthen legal and institutional systems for soil. Further, legal and institutional frameworks have emerged in many jurisdictions in recent years which can also be drawn upon to demonstrate various approaches to national environmental law reform and the design of legal and institutional frameworks. Developing a national soil strategy and setting up a national authority can also be done under such legislation.

\section{National soil strategy}

To achieve the general objectives of the global soil instrument, each party should be obliged to develop a national soil strategy to achieve the sustainable use of soil. ${ }^{70}$ They should integrate measures to achieve the sustainable use of soil into relevant sectoral or cross-sectoral plans, programmes and policies. ${ }^{71}$ It should specifically outline how a soil authority would operate, and express a commitment and obligation to achieve the sustainable use of soils as a major national environmental goal. A national soil strategy can also form the basis of a party's national reporting on soil conservation achievements.

\section{Establishing a national soil authority}

The establishment of an independent national authority for sustainable use of soils with responsibilities and functions to protect soil through a single specialist organisation would be the preferred option, but the responsibilities for managing soil could also be administratively dispersed among a number of different government agencies and ministries. The objective would be to give parties a duty of care and commitment to achieve sustainable use of soil. A national soil authority should be invested with a broad range of functions, with the right to determine, adjudicate, control and manage responsibilities to protect the soil environment. ${ }^{72}$

${ }^{64}$ See Global Soil Partnership, Intergovernmental Technical Panel on Soils,

<http://www.fao.org/globalsoilpartnership/intergovernmental-technical-panel-on-soils/en/>.

${ }^{65} \mathrm{Cf}$ art 5 Climate Change Convention 1992 on research and systematic observation; art 7 WCED Legal Principles 1986, <http://www.un-documents.net/ocf-a1.htm>; principles 9 and 12 Stockholm Declaration 1972; and principle 9 Rio Declaration 1992.

${ }^{66}$ See paras 34.15, 34.16 and 34.17 of Agenda 21, 1992

${ }^{67}$ See art 6 of the Declaration of Environmental Policies and Procedures Relating to Economic Development 1990.

${ }^{68}$ Convention on Access to Information, Public Participation in Decision-Making and Access to Justice in Environmental Matters 1998 ('Aarhus Convention').

${ }^{69}$ Hannam and Boer (2004), above n 42.

${ }^{70}$ See principles 7 and 16 of World Charter for Nature 1982.

${ }^{71}$ See principle 9 of World Charter for Nature 1982.

72 See I Hannam and Song Y, 'Report and Recommendations on Revising the 1991 Water and Soil Conservation Law of the People's Republic of China' (Technical Assistance to the People's Republic of China for the Implementation of the National Strategy for Soil and Water Conservation 4404, Asian Development Bank, 2006). 


\section{Other implementation tools}

Other implementation tools can include the development of national and subnational soil policies, obtaining information on soil security, soil assessment and planning, soil plans of management, codes of practice for sustainable use of soil, research into the sustainable use of soils, and monitoring the use of soil. ${ }^{73}$

\section{Identification and management of existing or potentially threatening processes}

A global soil instrument should encourage parties to develop procedures to identify and manage existing or potentially threatening processes to the sustainable use of soils, such as those mentioned in the introduction, above. Such a provision would promote procedures to prevent and manage existing or potentially threatening processes, and the type of action that must be taken to prevent environmental risks caused by damaging technologies, substances, processes and activities. ${ }^{74}$ It would require their identification and evaluation, and mandate the taking of measures to prevent significant environmental harm to soils.

\section{Disadvantaged people and communities}

This element would recognise that a particular level of economic well-being is a precondition for achieving the sustainable use of soils and is essential to meet the human rights issues associated with the degradation of soils. ${ }^{75}$ This would affirm the fundamental link between the sustainable use of soils and economic development ${ }^{76}$ and promote identification of vulnerable groups of people who may be viewed as disadvantaged in some way. ${ }^{77}$ It would deal with a number of societal situations and activities that directly or indirectly affect the sustainable use of soils. ${ }^{78}$ Under this definition, 'disadvantaged people' include: People who live and farm in a traditional manner; indigenous people who live close to the land; ${ }^{79}$ socio-economically disadvantaged people $;^{80}$ and women who work and manage the land.

States should thus prepare soil legislation with a sufficiently broad range of objectives to address the widely varying circumstances of disadvantaged people and communities. ${ }^{81}$

\section{Women's rights}

A global soil instrument should ensure that the role of women in promoting the sustainable use of soil receives adequate legal recognition and that this should be reflected in national soil legislation. ${ }^{82}$ Specifically, it should recognise the range of duties and responsibilities women perform under traditional and customary law, and the need for special assistance programs for receiving information, education and technical support for managing the soil environment. In addition, the right to own land or to legal occupancy, the right to enter into legal agreements on the use of soil, the procedure for participating in planning and decision-making processes, and the rights to obtain finance and secure loans, should be included.

\section{National action programmes}

National Action Programmes (NAPs) to address land degradation have been drawn up by a large number of countries through a consultative process. NAPs, as a specific tool to implement the objectives of the UNCCD, are important for the implementation of sustainable soil strategies as they have the advantage of reflecting the cross-cutting nature of land degradation at the national level (across economic sectors, administrative

\footnotetext{
${ }^{3}$ Hurni and Meyer (2012), above n 67.

${ }^{74}$ See, eg, arts 7(c) and 8(b) of the Convention on Biological Diversity 1992, and arts 5, 6, 10, 18.1-2 of Desertification Convention 1994.

75 UNCCD (2008), above n 84.

${ }^{76}$ See Preamble to Convention to Combat Desertification 1995 where Parties recognise that they are 'Conscious that sustainable economic growth, social development and poverty eradication are priorities of affected developing countries'. 77 See Hannam and Boer (2004), above 42, sec V.

${ }^{78} \mathrm{See}$, eg, Draft International Covenant on Environment and Development, Part VI 'Obligations Relating to Global Issues', in particular art 27 on 'Eradication of Poverty'.

${ }^{79}$ See J A Cohan, 'Environmental Rights of Indigenous Peoples under the Alien Tort Claims Act, the Public Trust Doctrine and Corporate Ethics, and Environmental Dispute Resolution' (2002) 20 UCLA Journal of Environmental Law and Policy 133 ; L Waters. 'Indigenous Peoples and the Environment: Convergence from a Nordic Perspective' (2002) 20 UCLA Journal of Environmental Law 237

80 See principles 8-14 of the Stockholm Declaration 1972 and principle 5 of the Rio Declaration 1992.

${ }^{81} \mathrm{See}$, eg, Republic of South Africa, Extension of Security of Tenure Act 1997; D A Posey, 'Traditional Resource Rights, International Instruments for Protection and Compensation for Indigenous Peoples and Local Communities' (IUCN, 1996).

82 See the Convention on the Elimination of All Forms of Discrimination against Women adopted in 1979 by the UN General Assembly, and has been referred to as an international bill of rights for women. Consisting of a preamble and 30 arts, it defines what constitutes discrimination against women and sets up an agenda for national action to end such discrimination <http://www.un.org/womenwatch/daw/cedaw/text/econvention.htm\#intro>; T Corral, 'Women's Sustainable Development Agenda' (2002) 26 Natural Resources Forum 249.
} 
border, and to identify local hotspots). The NAP process could provide for the preparation of a sustainable soil strategy, ${ }^{83}$ and should be provided for in a global soils instrument.

\section{Other mechanims for achieving sustainable soil use}

The 10-Year Strategic Plan and Framework to Enhance the Implementation of the Convention 2008-2018 This strategy was adopted by the UNCCD Conference of the Parties in September $2007 .{ }^{84}$ The 'strategic objectives' provide a framework to implement a strategy to achieve sustainable use of soil as they are a guide for the actions of all UNCCD stakeholders and partners over the period 2008-2018. The strategic objectives could be used to develop national methodologies to improve the living conditions of affected populations and the condition of affected ecosystems. The strategic objectives are supported by the 'operational objectives' of The Strategy that could provide a guideline for UNCCD stakeholders to achieve the strategic soil objectives.

The Strategic Plan for Biodiversity (2011-2020)

The Strategic Plan for Biodiversity (SPB) was adopted at the Convention on Biological Diversity Conference of the Parties 10 in 2010, and provides a framework for action by CBD stakeholders. ${ }^{85}$ The SPB is accompanied by 20 Biodiversity Targets (known as the Aichi Targets) where soil health/biodiversity is a cross-cutting theme amongst these targets including sustainable agriculture (Target 7), reducing pollution (Target 8), restoring and safeguarding ecosystem services (Target 14), and enhancing ecosystem resilience and health, including carbon storage and restoring 15 per cent of degraded ecosystems. ${ }^{86}$ Biodiversity can underpin many benefits to sustainable use of soil. As a cross-cutting approach, the Aichi Targets certainly could be used to establish specific targets for sustainable use of soil and the attainment of zero net land degradation.

\section{United Nations Forum on Forests beyond 2015}

It is also pertinent to note the developments within the United Nations Forum on Forests, which recently issued a Ministerial Declaration: The forests we want: Beyond 2015. ${ }^{87}$ The Declaration is clearly consistent with the aspirations expressed in this article for the conservation and sustainable use of soils. It affirms a strong commitment to the sustainable management of all types of forests so as to address major challenges. Many of the challenges identified are consistent with those confronting soils and the declaration recognises that these two environmental media are integrally related. The identified challenges are:

poverty eradication, economic growth and sustainable livelihoods, food security and nutrition, gender equality, cultural and spiritual values, health, water, energy production, climate change mitigation and adaptation, combating desertification, reduction of dust and sand storms, biodiversity conservation, sustainable soil and land management, watershed protection and disaster risk reduction. ${ }^{88}$

The declaration also expresses a major concern about the continued deforestation and degradation of forests in many regions (which is also one of the primary causes of soil degradation) and the need to reverse this trend. ${ }^{89}$ In the further development of international and national frameworks for soil law and policy, there is a clear need to take into account the interaction between forests and soils in order to address the sustainability of both.

\section{Nationally appropriate mitigation action under the UNFCCC}

The concept of Nationally Appropriate Mitigation Action (NAMA) emerged in 2007 under the UNFCCC Bali Action Plan, ${ }^{90}$ which called for 'Nationally Appropriate Mitigation Actions by developing country Parties in the context of sustainable development supported and enabled by technology, financing and capacity building, in a measurable, reportable and verifiable manner'. The 'UNFCCC Process' (defined by COPs since Bali), provides

${ }^{83}$ See Pak Low (ed), 'Economic and Social Impacts of Desertification, Land Degradation and Drought' (White Paper I, UNCCD 2nd Scientific Conference, 2013), sec 4, Policies and Strategies.

${ }^{84}$ See Report, 8th session, Conference of the Parties, Madrid 3-14 September 2007, ICCD/COP (8)/16/Add 1, 23 October 2007.

${ }^{85}$ Decision X/2 10th meeting of COP 18-29 October 2010 adopted a revised and updated Strategic Plan for Biodiversity, including the Aichi Biodiversity Targets, for the 2011-2020 period.

${ }^{86}$ COP11 called for major global efforts for ecosystem restoration, including restoring soils in agricultural systems being the major opportunity in terms of the current extent of degraded area, addressing social, economic and environment benefits and achieving multiple objectives.

${ }^{87}$ Draft ministerial declaration of the high-level segment of the $11^{\text {th }}$ session of the United Nations Forum on Forests, New York, 4-15 May 2015 Agenda item 8.

${ }^{88}$ Ibid, para 4.

${ }^{89}$ Ibid para 5.

${ }^{90}$ Report of the Conference of the Parties on its thirteenth session, held in Bali from 3 to 15 December 2007, Addendum, Part Two: Action taken by the Conference of the Parties at its thirteenth session, 1/CP.13 Bali Action Plan, para 1(b)(2). 
a guide as to the type of NAMAs that are relevant to achieving sustainable use of soil, including for developing countries to undertake comprehensive land management mitigation actions. These are to be nationally appropriate; that is, tailored to countries' national circumstances and in line with UNFCCC's principle of common but differentiated responsibilities. They are to take place in the context of sustainable development, meaning they are to be embedded in the countries' broader sustainable development strategies, and to this extent can include targets to achieve sustainable use of soil. ${ }^{91}$

\section{Conclusion}

On examination of current international environmental law and national legal frameworks, it is clear that legal regimes for conservation and sustainable use of soil are generally inadequate worldwide, although isolated cases of effective legislation exist. ${ }^{92}$ While the level of discussion about a global instrument for soil has been heightened in recent years, more attention is needed to broadcast the fundamental role of soils and the achievement of zero net land degradation in achieving food security, biodiversity conservation and mitigation of climate change. This article has indicated that there are many provisions in existing global and regional legal instruments, as well as soft law, that can be drawn on to frame a specialised instrument for soil. What is needed is the political will to create an instrument for soil that places it on the same level as biological diversity and climate change.

If the protection of soil is to become 'a solid component of the post-2015 development agenda', as urged in Global Soil Week 2015, ${ }^{93}$ the moment has arrived in which to seriously consider a comprehensive legal regime at international, regional and national levels to translate the scientific and policy prescriptions that have been put forward in recent years into viable, enforceable regulatory frameworks. However, in order to move ahead with such an initiative, an attitudinal paradigm shift is required at community, governmental and legislative levels to substantially lift the focus on the globally vital importance of soil.

\footnotetext{
${ }^{91}$ See I Hannam, 'Legal and Policy Framework to Support a Livestock/Grassland National Appropriate Mitigation Action in Mongolia' (ADB R-CDTA 7534: Strengthening Carbon Financing for Regional Grassland Management in Northeast Asia, Asian Development Bank, 2012).

92 Hannam and Boer (2002), above n 34; see also B Boer and I Hannam, 'Legal Aspects of Sustainable Soils: International and National' (2003) 12(2)) Review of European, Comparative and International Environmental Law 149; and B Boer and I Hannam, A Draft Soil Convention, Rio+20: What Ambition for the Environment? (Third Worldwide Conference of Environmental Law NGO and Lawyers, Limoges, 29 September - 1 October 2011) <https://portals.iucn.org/2012forum/ sites/2012forum/files/paper-soil-protocol-cidce-limoges-rio-20-symposium-final-25-august-2011-1.pdf>.

93 Thomas Silberhorn, ‘Keynote Speech' Global Soil Week Bulletin (2015) 206 4, <http://www.iisd.ca/soil/gsw3/html/crsvol206num3e.html>.
} 